\title{
MOBILIDADE PENDULAR NA REGIÃO METROPOLITANA DA BAIXADA SANTISTA: UMA ANÁLISE COMPARATIVA DOS DADOS CENSITÁRIOS DE 2000 E 2010
}

\author{
MOVILIDAD PENDULAR EN LA REGIÓN METROPOLITANA DE LA BAIXADA \\ SANTISTA: UN ANÁLISIS COMPARATIVO DE LOS DATOS CENSITARIOS DE \\ 2000 Y 2010
}

PENDULAR MOBILITY IN THE BAIXADA SANTISTA METROPOLITAN REGION: A COMPARATIVE ANALYSIS OF 2000 AND 2010 CENSUS DATA

\author{
Maíra Darido da CUNHA ${ }^{1}$ \\ João Roberto Monteiro da Silva BARBOSA ${ }^{2}$
}

RESUMO: O presente trabalho propõe apresentar uma análise comparativa dos movimentos pendulares entre os municípios da Região Metropolitana da Baixada Santista, com base nos dados censitários dos anos de 2000 e 2010. Pretende-se, a partir dessas informações, apresentar a população que diariamente se desloca entre as cidades que compõem a região e identificar as taxas de saída e entrada nos referidos municípios.

PALAVRAS-CHAVE: Baixada Santista. Mobilidade populacional. Movimento pendular.

RESUMEN: El presente trabajo propone presentar un análisis comparativo de los movimientos pendulares entre los municipios de la Región Metropolitana de la Baixada Santista, con base en los datos censales de los años 2000 y 2010. Se pretende, a partir de esas informaciones, presentar la población que diariamente se desplaza entre las ciudades que componen la región e identificar las tasas de salida y entrada en los referidos municipios.

PALABRAS CLAVE: Bajada Santista. Movilidad poblacional. Movimiento pendular.

ABSTRACT: The present work proposes to present a comparative analysis of the commuting movements between the municipalities of the Metropolitan Region of Baixada Santista, based on the census data of the years 2000 and 2010. It is intended, from this information, to present the population that daily moves between the cities that compose the region and identify the exit and entry taxes in said municipalities.

\footnotetext{
${ }^{1}$ Universidade Estadual Paulista (UNESP), Araraquara - SP - Brasil. Doutoranda em Política e Gestão pelo Programa de Pós-Graduação em Educação Escolar. ORCID <https://orcid.org/0000-0002-8263882X>. E-mail: maira_darido@yahoo.com.br

${ }^{2}$ Universidade Federal do ABC (UFBAC), Santo André - SP - Brasil. Doutorando em Planejamento e Gestão do Território. ORCID <https://orcid.org/0000-0001-7987-455X>. E-mail: jrmsbarbosa@gmail.com
} 
KEYWORDS: Baixada Santista. Population mobility. Pendular movement.

\section{Introdução}

$\mathrm{Na}$ segunda metade do século XX, o Brasil passou por significativas transformações que alteraram sua estrutura urbana, sendo esse processo profundamente marcado por grandes fluxos migratórios que se dirigiam do campo para as cidades. Esse intenso processo de urbanização foi o resultado de diversas mudanças na economia industrial e agrícola que ocorreram principalmente na década de 1960.

Com o processo de urbanização e industrialização marcado, principalmente a partir da década de 1980, nota-se uma nova configuração do padrão migratório do Brasil, sendo possível observar a diminuição dos fluxos migratórios inter-regionais e o consequente aumento das migrações de curta distância (RIBEIRO et al, 2015).

Dessa forma, os estudos sobre mobilidade pendular no Brasil ganharam impulso devido à necessidade de se compreender esses novos processos. Nesta esteira, optou-se por utilizar o conceito de mobilidade pendular como forma de definir os deslocamentos dos indivíduos do local de residência para outro lugar, por motivo de estudo ou trabalho, medidos em termos de frequência semanal, tempo e espaço de deslocamento (JARDIM, 2011).

Na Região Metropolitana da Baixada Santista (RMBS) o estudo da mobilidade pendular ganha importância devido aos recentes processos de transformações urbanas e demográficas que a região vem sofrendo. De um lado, dados censitários demonstram uma redução de crescimento populacional nos municípios considerados centrais, sendo que a população de Santos, cidade-polo, permanece praticamente a mesma desde a década de 1980. Por outro lado, observou-se um forte crescimento populacional nas áreas periféricas da região, mas com manutenção da concentração das atividades produtivas e do emprego no núcleo regional.

O padrão de crescimento percebido também pode estar relacionado com a migração intrametropolitana na RMSB, com um saldo migratório negativo do município de Santos e deslocamento populacional da cidade-polo em direção à periferia metropolitana, onde o custo da terra e para manutenção da vida são mais baratos (VAZQUEZ, 2011). Sendo assim, os movimentos pendulares relacionam-se com a expansão do espaço urbano, e, consequentemente, geram novas dinâmicas no território e na integração entre os municípios da região. 


\section{Movimentos pendulares na região metropolitana da baixada santista}

Para caracterizar o movimento pendular na Região Metropolitana da Baixada Santista, serão apresentadas as dimensões desse fenômeno e seu crescimento na última década, entre os anos 2000 e 2010. Para tanto, buscou-se dimensionar os movimentos de entrada e saída em cada município da RMBS, das viagens por motivo de trabalho e/ou estudo, buscando identificar as possíveis explicações para a intensificação desses fluxos entre os municípios da região.

Tabela 1 - Total de pessoas que saem do município para trabalhar e/ou estudar, 2000 e 2010

\begin{tabular}{l|cc|cc}
\hline \multirow{2}{*}{ Município } & \multicolumn{2}{|c|}{ Ano } & \multicolumn{2}{c}{$\begin{array}{c}\text { Porcentual sobre a } \\
\text { população total }(\%) \\
\end{array}$} \\
\hline Bertioga & 2000 & 2010 & 2000 & 2010 \\
\hline Cubatão & 800 & 1.903 & 2,66 & 3,99 \\
Guarujá & 8.202 & 13.328 & 7,57 & 11,23 \\
Itanhaém & 18.872 & 25.863 & 7,13 & 8,9 \\
Mongaguá & 1.973 & 6.341 & 2,74 & 7,28 \\
Peruíbe & 1.534 & 4.767 & 4,37 & 10,3 \\
Praia Grande & 1.165 & 3.777 & 2,26 & 6,32 \\
Santos & 18.624 & 38.503 & 9,62 & 14,69 \\
São Vicente & 27.340 & 40.226 & 6,54 & 9,59 \\
& 55.742 & 82.320 & 18,36 & 24,76 \\
Total & 134.25 & 217.02 & 9,09 & 13,04 \\
\hline
\end{tabular}

Fonte: IBGE - Censo demográfico 2000 e 2010

Os dados da tabela 01 mostram os contingentes populacionais que realizam movimento pendular, identificados nos dois últimos censos. Constatou-se que, em 2000, a população que realizava movimento pendular correspondia a 134.252 pessoas $(9,1 \%$ da população total). Segundo o Censo de 2010, cerca de 217.028 pessoas se deslocavam para outros municípios, representando $13 \%$ da população total da região.

Vale indicar que os municípios da região apresentaram um incremento na quantidade de pessoas que realizam movimentos pendulares, em especial nas cidades de Cubatão, Praia Grade e São Vicente, que apresentaram a maior concentração de pessoas que se deslocam diariamente para saída, representando cerca de 50\% no total de saída para outros municípios dentro da RMBS. 
Analisando a tabela 1, entende-se que a mobilidade para outros municípios entre 2000 e 2010 foi maior em São Vicente, Mongaguá e Praia Grande, respectivamente. Chama atenção também o caso do município de Bertioga que apresentou menor movimento pendular proporcional em 2000 e 2010, seguido por Itanhaém e Peruíbe, o que indica a menor intensidade desse processo nos municípios mais distantes da cidade polo, uma vez que o dispêndio de tempo e dinheiro para o deslocamento é maior.

Porém, apesar do patamar menor, observou-se um grande aumento na quantidade de pessoas que realizam movimento pendular nesses municípios. No entanto, devido à maior incidência, o destaque é o crescimento de $106,7 \%$ observado no município de Praia Grande. Em São Vicente, o incremento do movimento pendular foi de cerca de $50 \%$, alcançando cerca de um quarto da população total em 2010. No município de Guarujá, o aumento percebido é de 37\% e em Santos, muito embora o fenômeno alcance menos de $10 \%$ da população, o crescimento observado durante a última década pode ser considerado alto, de $47 \%$.

Sem dúvida, as viagens por motivo de trabalho possuem um grande peso. Em 2010 , cerca de 174.674 pessoas (23,4\% da população ocupada) deslocam-se diariamente para trabalhar em um município diferente de seu município de residência. Uma década antes o percentual de pessoas que trabalhavam em outro município era de 18\% (105.556 pessoas).

Visando a destacar a importância da saída por motivo de trabalho, o mapa 01 mostra a proporção da população que faz movimento pendular em direção a outro município. Tal relação é denominada de taxa de repulsão para o trabalho. Observa-se que a maior saída é de São Vicente, onde $46,93 \%$ das pessoas ocupadas se deslocam diariamente para outros municípios por motivos exclusivos de trabalho.

Figura 1 - Mapa: taxa de repulsão para trabalho em 2010

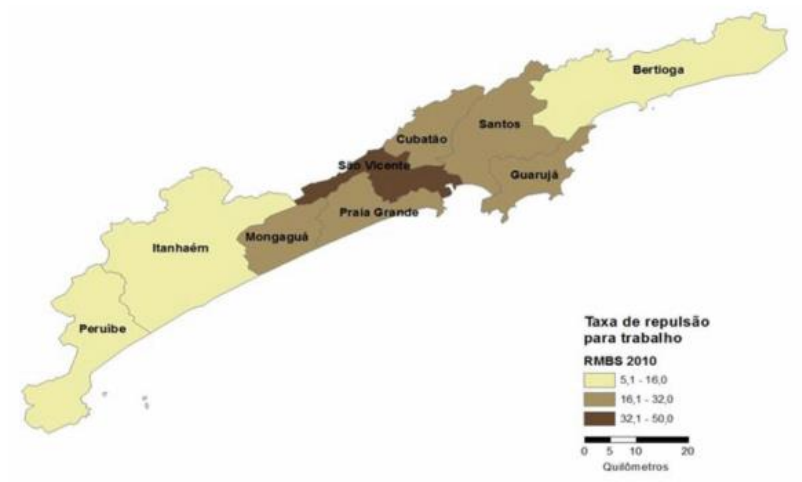

Fonte: RMBS (2010) 
O intenso fluxo de saída da cidade de São Vicente pode ser explicado (i) pela ausência de atividade econômica especializada, ou seja, para além do consumo interno e (ii) pela proximidade das cidades com maior poder de atração, como Santos e Cubatão. Dessa forma, o município pode ser considerado um exemplo de cidade-dormitório, pois apresenta uma alta ocupação territorial e localização estratégica.

Tradicionalmente, utiliza-se o termo cidade-dormitório para caracterizar cidades nas quais uma significativa parcela da população realiza movimento pendular para outro município, onde existe sempre uma relação de desvantagem econômica e social em relação à cidade-polo, que atrai a grande maioria dos fluxos pendulares. A origem dessas cidades estaria marcada pelos processos de urbanização e consequentemente dos processos de periferização das regiões metropolitanas, onde a especulação imobiliária e o alto preço do solo exerceram papéis fundamentais para a consolidação de tais processos (OJIMA; PEREIRA; SILVA, 2007).

Dessa forma, podemos afirmar que há um vínculo direto entre a cidade principal e as demais que condicionam os fluxos diários e que servem como elemento de manutenção da integração da região. Logo, se estabelece uma relação entre Santos e São Vicente, conceituada pelo autor como resultado de um processo de conturbação. Processo esse que se caracteriza como um espaço contínuo com intensos fluxos de pessoas entre os municípios (SILVA, 2008).

O município de Praia Grande, depois de São Vicente, apresenta o maior percentual de moradores que trabalham em outro município, e sua taxa de repulsão para o trabalho é de 26,37\%, de acordo com as informações censitárias do ano de 2010. As razões são semelhantes, mas a intensidade é menor devido à distância. Contudo, vale destacar o grande aumento de saída (mais que o dobro) de Praia Grande entre 2000 e 2010.

Do mesmo modo, essa tendência pode ser observada em estudo sobre as regiões metropolitanas de São Paulo, sendo comprovado que, dentro da macrometrópole paulista, as origens dos movimentos pendulares mais relevantes partem sempre dos municípios médios. O relatório também destaca que, mesmo em um contexto de redução de crescimento demográfico das regiões metropolitanas, ocorreu um aumento do volume dos movimentos pendulares entre 2000 e 2010; demonstrando que, embora o fenômeno esteja extremamente interligado a processos de crescimento populacional e expansão urbana, não está dependente de um crescimento populacional (NEPO/UNICAMP, 2013). 
Pelo lado da entrada, a tabela 02 identifica quais são os municípios da região que mais recebem pessoas oriundas de outros municípios por motivos de trabalho e/ou estudo. Esses dados se tornam importantes para investigar quais são os destinos dos movimentos pendulares, em razão da atração das atividades econômicas localizadas em cada município.

Assim, segundo Barcellos e Jardim (2008), há uma expectativa de que a cidadepolo exerça maior poder de atração, segundo os autores os estudos sobre mobilidade pendular em outras regiões metropolitanas do Brasil apontam que os fluxos estão sempre direcionados a localidades que concentram atividades econômicas e infraestrutura, centralizando oportunidades, principalmente de trabalho.

Tabela 02 - Total de pessoas que entram no município para trabalhar e/ou estudar em 2000 e 2010

\begin{tabular}{|c|c|c|c|c|}
\hline \multirow[t]{2}{*}{ Município } & \multicolumn{2}{|r|}{ Ano } & \multicolumn{2}{|c|}{$\begin{array}{l}\text { Porcentual sobre a } \\
\text { população total }\end{array}$} \\
\hline & 2000 & 2010 & 2000 & 2010 \\
\hline Bertioga & 1.863 & 3.083 & 6,2 & 6,47 \\
\hline Cubatão & 17.350 & 31.422 & 16,02 & 26,47 \\
\hline Guarujá & 5.447 & 8.127 & 2,06 & 2,8 \\
\hline Itanhaém & 1.001 & 2.326 & 1,39 & 2,67 \\
\hline Mongaguá & 1.567 & 2.310 & 4,46 & 4,99 \\
\hline Peruíbe & 1.222 & 2.850 & 2,38 & 4,77 \\
\hline Praia Grande & 5.827 & 10.172 & 3,01 & 3,88 \\
\hline Santos & 75.685 & $0^{118.30}$ & 18,11 & 28,21 \\
\hline São Vicente & 8.910 & 15.931 & 2,94 & 4,79 \\
\hline Total & 118.872 & 194.521 & 8,05 & 11,69 \\
\hline
\end{tabular}

Fonte: IBGE - Censo demográfico 2000 e 2010

O município de Santos é o destino de $60 \%$ das pessoas que se deslocam por motivo de emprego ou estudo entre os municípios da RMBS. A segunda cidade com maior poder de atração é Cubatão, destino de $16 \%$ do movimento pendular da região. Juntas, representam mais de $75 \%$ dos deslocamentos no espaço metropolitano.

Duas explicações podem ser dadas, ambas relacionadas com a questão econômica: (i) a concentração das atividades de comércio e serviços, incluído o setor 
portuário, no município de Santos e (ii) a concentração, em Cubatão, quase que da totalidade da atividade econômica industrial da região.

Considerando apenas os movimentos pendulares por motivo de trabalho, o mapa 02 indica a taxa de atração dos municípios da RMBS, que corresponde ao total de entradas no município em relação à população ocupada. Observa-se que Santos e Cubatão são os municípios com maior destaque. Do outro lado, Guarujá e Itanhaém são os que exercem menor atração.

Figura 2 - Mapa: taxa de atração para trabalho em 2010

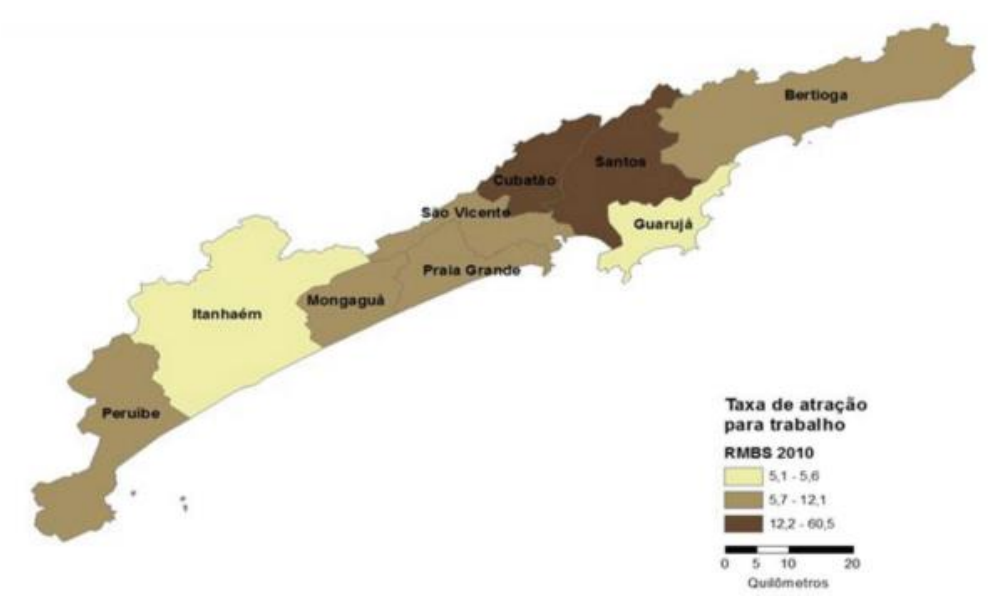

Fonte: RMBS (2010)

Em relação às consequências da intensidade do movimento pendular no cotidiano da população, pode-se tomar como exemplo o município de Santos, que, em 2000, recebia diariamente cerca de 75.685 pessoas provenientes de outros municípios da RMBS; em 2010, esse número saltou para 118.300 pessoas, o que significa um incremento de $28,2 \%$ de pessoas em seu território diariamente. Certamente, isso influencia na dinâmica da cidade e, mais diretamente, no aumento do trânsito, levando à dificuldade de mobilidade urbana que o município enfrenta.

$\mathrm{Na}$ relação entre entradas e saídas do movimento pendular, por meio da comparação entre as tabelas 01 e 02, os municípios que tiveram saldo negativo, ou seja, mais saídas do que entradas, foram: Guarujá, Itanhaém, Mongaguá, Peruíbe, Praia Grande e São Vicente. Por outro lado, as cidades de Santos, Cubatão e Bertioga são os municípios com saldo positivo, onde as entradas superam as saídas do movimento pendular, conforme demonstrado na tabela a seguir. 
Tabela 3 - Número de pessoas que entram e saem dos municípios para trabalho e/ou estudo, anos de 2000 e 2010

\begin{tabular}{l|lll|cll}
\hline \multirow{2}{*}{ Município } & \multicolumn{3}{|c|}{ Censo 2000} & \multicolumn{3}{c}{ Censo 2010 } \\
& Entrada & Saída & Saldo & Entrada & Saída & Saldo \\
\hline Bertioga & 1.863 & 800 & 1.063 & 3.083 & 1.903 & 1.180 \\
Cubatão & 17.350 & 8.202 & 9.148 & 31.422 & 13.328 & 18.094 \\
Guarujá & 5.447 & 18.872 & 13.425 & 8.127 & 25.863 & 17.736 \\
Itanhaém & 1.001 & 1.973 & 972 & 2.326 & 6.341 & 4.015 \\
Mongaguá & 1.567 & 1.534 & 33 & 2.310 & 4.767 & 2.457 \\
Peruíbe & 1.222 & 1.165 & 57 & 2.850 & 3.777 & 927 \\
Praia Grande & 5.827 & 18.624 & 12.797 & 10.172 & 38.503 & 28.331 \\
Santos & 75.685 & 27.340 & 48.345 & 118.300 & 40.226 & 78.074 \\
São Vicente & 8.910 & 55.742 & 46.832 & 15.931 & 82.320 & 66.389 \\
Total & 118.872 & 134.252 & 15.380 & 194.521 & 217.028 & 22.507 \\
\hline
\end{tabular}

Fonte: IBGE - Censo demográfico 2000 e 2010

Na Região Metropolitana da Baixada Santista, a cidade de Santos exerce a função de cidade-polo e, portanto, tem o maior saldo positivo entre os fluxos de movimentos pendulares, devido à grande concentração de atividades econômicas em seu espaço urbano. Tal fenômeno cresceu nos anos 2000 e o saldo positivo cresceu em mais de $60 \%$ no período analisado.

Em termos de força de atração para trabalho, apesar de não apresentar um número expressivo se comparado a Santos, é fundamental destacar o município de Cubatão. Segundo as informações dispostas na tabela 02, em 2000 cerca de 17.350 pessoas deslocavam-se diariamente para o município, enquanto em 2010 esse número cresceu para 31.422 pessoas. O saldo positivo praticamente dobrou entre 2000 e 2010.

Embora o movimento pendular também tenha aumentado nos municípios de Guarujá e Bertioga, esses dois municípios foram os que tiveram os menores incrementos de saldo entre 2000 e 2010 (32\% e 11\%, respectivamente), o que reforça o argumento de arrefecimento do eixo de expansão norte (JAKOB, 2003).

Por outro lado, o eixo sul é o que apresenta maior força. Apesar do patamar baixo, os três municípios do Litoral Sul — Peruíbe, Itanhaém e Mongaguá - são os que mais tiveram crescimento no saldo do movimento pendular - todos negativos em 2010. No entanto, o município de Praia Grande se destaca por dois motivos: a) pelo segundo maior saldo negativo, o que indica que se torna cada vez mais opção de cidade- 
dormitório, devido à ocupação do espaço urbano de São Vicente; b) pelo aumento do saldo negativo de mais de $120 \%$ entre 2000 e 2010.

\section{Considerações finais}

Ao analisar os dados, observa-se que a mobilidade pendular fornece evidências de como o tecido social é constituído sobre o espaço urbano, onde o modo de expansão urbana cria uma distância necessária entre o lugar de residência e o de trabalho (BRITO; SOUZA, 2005). Na RMBS, o volume e o aumento da intensidade do movimento pendular nos anos 2000 indicam um aumento importante do nível de integração entre os municípios da região.

Assim, pode-se concluir que, na Região Metropolitana da Baixada Santista, o aumento dos fluxos pendulares se relaciona com os processos de redistribuição populacional influenciados pela dinâmica do mercado imobiliário e pela ação do Estado, onde tais elementos são decisivos para a organização social do espaço.

Apesar de a mobilidade pendular ser considerada um importante elemento para superar as adversidades encontradas nos municípios de origem, deve-se observar que o aumento dos fluxos gera aumento do trânsito, e a dificuldade de locomoção, devido à insuficiência do sistema de transporte público e à falta de ampliação dos sistemas viários na região, acarreta uma crise de mobilidade urbana, especialmente nas vias de acesso, avenidas e ruas principais dos municípios que exercem grande atração para os fluxos, como é o caso dos municípios de Santos e Cubatão.

\section{REFERÊNCIAS}

ANTICO, C. Deslocamentos pendulares nos espaços sub-regionais da região metropolitana de São Paulo. In: Encontro Nacional de Estudos Populacionais. Caxambú, 2004.

ANTICO, C. Onde morar e onde trabalhar: espaço e deslocamentos pendulares na região metropolitana de São Paulo. 2003. 248 f. Tese (Doutorado) - Instituto de Filosofia e Ciências Humanas da Universidade Estadual de Campinas, Campinas, 2003.

BARCELLOS, T.; JARDIM, M. Movimentos pendulares no Rio Grande do Sul: um foco sobre aglomerações urbanas. In: XVI Encontro Nacional de Estudos

Populacionais. Caxambú, 2008. 
RIBEIRO, L. C.; BRANDÃO, M. V.; DE MORELL, M. G. G.; SANTOS, A. R. Baixada Santista: transformações na ordem urbana / organização - 1. ed. - Rio de Janeiro: Letra Capital: Observatório das Metrópoles, 2015.

BRASIL. IBGE - Instituto Brasileiro de Geografia e Estatística. Censo Demográfico, 2000.

BRASIL. IBGE - Instituto Brasileiro de Geografia e Estatística. Censo Demográfico, 2010.

BRITO, F. As migrações internas no Brasil: um ensaio sobre os desafios teóricos recentes. Belo Horizonte: UFMG/Cedeplar, (texto para discussão n. 366), 2009.

BRITO, F.; SOUZA, J. Expansão urbana nas grandes metrópoles: o significado das migrações intrametropolitanas e da mobilidade pendular na reprodução da pobreza. São Paulo em Perspectiva, São Paulo, v. 19, p. 48-63, 2005.

CUNHA, J. M. P. Redistribuição espacial da população: tendências e trajetória. São Paulo em Perspectiva, v. 17, n. 3-4, p 218-233, 2003.

CUNHA, J. M. P.; SOBREIRA, D. A metrópole e seus deslocamentos populacionais cotidianos: o caso da mobilidade pendular na Região Metropolitana de Campinas em 2000. 2007. Disponível em:

$<$ http://www.abep.nepo.unicamp.br/docs/anais/outros/5EncNacSobreMigracao/comunic _sec_1_met_des_pop.pdf>. Acesso em: 10 out. 2018.

HOGAN, D. J. Quem paga o preço da poluição? Uma análise de residentes e migrantes pendulares em Cubatão. In: VII Encontro Nacional de Estudos Populacionais. Caxambú, 1990.

JAKOB, A. A. E. Vetores de expansão urbana e fluxos migratórios na Baixada Santista. In: Questão urbana na Baixada Santista: políticas, vulnerabilidades e desafios para o desenvolvimento. Santos: Editora Leopoldianum/ Universidade Católica de Santos, 2011.

JAKOB, A. A. E. Análise sócio-demográfica da constituição do espaço urbano da região metropolitana da Baixada Santista no período 1960-2000. Campinas: Núcleo de Estudos de População/Unicamp, p. 134 (texto para discussão n. 45), 2003.

JARDIM, A. Reflexões sobre mobilidade pendular. In: Reflexões sobre os deslocamentos populacionais no Brasil, 2011. Disponível em:

$<$ http://www.ibge.gov.br/

home/estatistica/populacao/reflexos_deslocamentos/deslocamentos.pdf>. Acesso em: 10 out. 2018.

NEPO. O fenômeno da mobilidade pendular na Macrometrópole do Estado de São Paulo: uma visão a partir das quatro regiões metropolitanas oficiais. Relatório de Pesquisa. Universidade Estadual de Campinas: Núcleo de Estudos de População, 2013. Disponível em: <www.nepo.unicamp.br>. Acesso em: 10 set. 2018. 
OJIMA, R.; PEREIRA, R. H.; SILVA, R. B. A mobilidade pendular na definição das cidades dormitórios: caracterização sociodemográfica e novas territorialidades no contexto da urbanização brasileira. In: V Encontro Nacional sobre Migrações. Universidade Estadual de Campinas - UNICAMP. Campinas, 2007.

SILVA, R. B. Mobilidade pendular; população e vulnerabilidade socioambiental na RMBS: um olhar sobre Cubatão. In: XVI Encontro Nacional de Estudos Populacionais. Caxambú, 2008.

SILVA, R. B. Vulnerabilidades e mobilidade pendular na região metropolitana da Baixada Santista. 2009. 112 f. Tese (Doutorado) Universidade Estadual de Campinas. Campinas, 2009.

VAZQUEZ, D. A. Tendências demográficas e socioeconômicas nos municípios da Baixada Santista. In: VAZQUEZ, D. A. (Org.). A questão urbana na Baixada Santista: políticas, vulnerabilidades e desafios para o desenvolvimento. Santos/ SP: Editora Leopoldianum / Universidade Católica de Santos, 2011.

\section{Como referenciar este artigo}

CUNHA, Maíra Darido da.; BARBOSA, João Roberto Monteiro da Silva. Mobilidade pendular na Região Metropolitana da Baixada Santista: Uma análise comparativa dos dados censitários de 2000 a 2010. Rev. Sem Aspas, Araraquara, v. 7, n. 1, p. 145-155, jan./jun., $2018 . \quad$ ISSN: $2358-4238 . \quad$ DOI: 10.29373/semaspas.unesp.v7.n1.jan/jun.2018.11472

Submetido em: 13/06/2018

Aprovado em: 08/11/2018 